\title{
Association of serum levels of antibodies against ALDOA and FH4 with transient ischemic attack and cerebral infarction
}

Hao Wang

Jinan University

Hao Lu

Jinan University

Xiao-Meng Zhang

Chiba University

Ken-ichiro Goto

Chiba University

Eiichi Kobayashi

Chiba University

Yoichi Yoshida

Chiba University

Akihiko Adachi

Chiba University

Tomoo Matsutani

Chiba University

Yasuo Iwadate

Chiba University

Seiichiro Min

Chiba University

Toshio Machida

East Chiba Medical Center

Mizuki Sata

Osaka University

Kazumasa Yamagishi

University of Tsukuba

Hiroyasu Iso

Osaka University

Norie Sawada

National Cancer Center

Shoichiro Tsugane 
National Cancer Center

\section{Ikuo Kamitsukasa}

Chibaken Saiseikai Narashino Hospitao

\section{Takeshi Wada}

Chiba AOba Municipal Hospital

\section{Akiyo Aotsuka}

Chiba Aoba Municipal Hospital

\section{Kazuo Sugimoto}

Beijing University of Chinese Medicine

\section{Hirotaka Takizawa}

Port Square Kashiwado Clinic

\section{Koichi Kashiwado}

Kashiwado Hospital

\section{Hideo Shin}

Higashi Funabashi Hospital

\section{Go Tomiyoshi}

Fujikura Kasei Co.

\section{Rika Nakamura}

Fujikura Kasei Co.

\section{Natsuko Shinmen}

Fujikura Kasei Co.

\section{Hideyuki Kuroda}

Fujikura Kasei Co.

\section{Anding Xu}

Jinan University

Takaki Hiwasa ( $\nabla$ hiwasa_takaki@faculty.chiba-u.jp )

Chiba University https://orcid.org/0000-0002-0475-3881

\section{Research article}

Keywords: transient ischemic attack, cerebral infarction, ALDOA, FH, antibody biomarker

Posted Date: August 31st, 2020

DOI: https://doi.org/10.21203/rs.3.rs-18584/v2

License: (c) (1) This work is licensed under a Creative Commons Attribution 4.0 International License. Read Full License 
Version of Record: A version of this preprint was published at BMC Neurology on July 9th, 2021. See the published version at https://doi.org/10.1186/s12883-021-02301-w. 


\section{Abstract}

Background: Ischemic stroke, such as transient ischemic attack (TIA) and acute-phase cerebral infarction $(\mathrm{aCl})$, are the serious problems in the aging society. Therefore, development of biomarkers for TIA and $\mathrm{aCl}$ are attempted.

Methods: Candidate antigens recognized by IgG autoantibodies in the serum of 19 TIA patients were screened by a human aortic endothelial cell cDNA library. Serum antibody levels against the antigens were examined by amplified luminescent proximity homogeneous assay-linked immunosorbent assay (AlphaLISA) in healthy donor (HD), TIA, and aCl cohorts ( $n=285,92$ and 529). The antibody levels in the sera of the Japan Public Health Center-based Prospective Cohort Study (JPHC) from 1991 to 1993 was also examined.

Results: Aldolase A, fructose-bisphosphate (ALDOA) and fumarate hydratase (FH) were identified as the candidate antigens. AlphaLISA revealed that the levels of anti-ALDOA antibodies (ALDOA-Abs) and anti$\mathrm{FH}$ antibodies (FH-Abs) were both higher in patients with TIA or aCl than those in HDs $(\mathrm{P}<0.05)$. The levels of ALDOA-Abs [odds ratio (OR): 2.46, $\mathrm{P}=0.0050$ ] and FH-Abs (OR: 2.49, $\mathrm{P}=0.0037$ ) were independent predictors of TIA by multivariate logistic regression analysis. The case-control study showed the levels of ALDOA-Abs (OR: 2.50, P < 0.01) and FH-abs (OR: 2.60, P < 0.01) were associated with risk of $\mathrm{aCl}$. Correlation analysis demonstrated that both ALDOA-Abs and FH-Abs were well associated with hypertension, coronary heart disease and habitual smoking. These antibody levels were also correlated well with maximum intima-media thickness, which reflects atherosclerotic stenosis.

Conclusions: ALDOA-Abs and FH-Abs can serve as novel potential biomarkers for prediction of atherosclerotic TIA and $\mathrm{aCl}$.

\section{Background}

Ischemic stroke, such as Transient ischemic attack (TIA) and cerebral infarction (CI), are the most common cerebrovascular disorders worldwide. TIA is a transient episode of neurological dysfunction caused by focal brain, spinal cord, or retinal ischemia, without acute infarction [1]. $\mathrm{Cl}$ is an episode of neurological dysfunction caused by focal brain infarction, which is a major cause of fatality and disability [2]. Patients with TIA are at high risk of $\mathrm{Cl}$. Epidemiologic studies revealed that the prevalence of prior TIA ranged from $15 \%$ to $30 \%$ among patients who present with $\mathrm{Cl}$. Additionally, the risk of $\mathrm{Cl}$ on the 7th, 30th, and 90th-day post-TIA was $2.0 \%$ to $8.0 \%, 8.0 \%$ to $13.5 \%$, and $9.5 \%$ to $20.1 \%$, respectively $[3,4]$. TIA with progressive aggravation represents an early warning signal for $\mathrm{Cl}$. Therefore, the key to reduce ischemic stroke's influence on human health is early diagnosing TIA and predicting the onset of $\mathrm{Cl}[5]$.

To date, there are many means of early prediction for TIA and $\mathrm{Cl}$ in the medical field, including modern imaging techniques (e.g., transcranial Doppler [6], computed tomography, magnetic resonance imaging [7], cerebral angiography [8]); blood biochemical indicators (e.g., oxidatively modified low-density lipoprotein [9], homocysteine [10], lipoprotein-related phospholipase A2, C-reactive protein [11], heat shock 
protein [12]); and comprehensive assessment of risk factors [13] (e.g., hypertension (HT), hyperlipidemia, body mass index (BMI), obesity, smoking habits, family history). However, the above-mentioned methods are frequently insufficient to represent standard approaches for early diagnosis of TIA and prediction of the onset of $\mathrm{Cl}$. Therefore, it is usually expected to find novel biomarkers that would largely improve the management and prognosis of such patients [14].

It is well documented that atherosclerosis is highly likely to play a key role in the pathogenesis of ischemic stroke, and most incident ischemic stroke (i.e. TIA and $\mathrm{Cl}$ ) are based on the atherosclerosis [15]. Atherosclerosis is not only a simple pathological process of lipid deposition in the vascular wall. However, the most recent accomplishments have indicated that atherosclerosis is an inflammatory proliferative dynamic mechanism induced by an excessive autoimmune response following the injury of vascular endothelial cells and smooth muscle cells [16]. Endogenous antigens cause autoimmune responses significantly influencing the development process of atherosclerosis, which ultimately leads to narrow or blockage of the offending artery [17]. Of note: autoantibodies induced by the antigens have been detected in the serum of patients with atherosclerosis-related diseases, such as $\mathrm{Cl}$, coronary heart disease (CHD) and diabetes mellitus (DM) [18].

An established method for identifying endogenous antigenic proteins is the serological identification of antigens by recombinant cDNA expression cloning (SEREX), which represents a combination of molecular cloning and serological typing by using phage expression libraries [19]. The method was originally developed to screen out tumor-associated antigens, which has been used to identify more than 2,300 novel tumor antigens in a public access online database known as the Cancer Immunome Database $[20,21]$. And so, it is considered one of the most effective methods for the identification of antigenic targets on a genome scale [22-30]. As a result, it has also been used for autoimmune diseases, such as systemic lupus erythematosus, Kawasaki disease, Bechet's disease, and multiple sclerosis in the recent years [22-25]. In earlier studies, we used SEREX for atherosclerosis-related diseases and for the identification of antibodies against RPA2 [26], MMP1, CBX1 and CBX5 [27] in Cl, and ATP2B4, BMP-1 [28], TUBB2C [29] and SH3BP5 [30] in other atherosclerosis-related diseases.

Both TIA and $\mathrm{Cl}$ have the pathological basis of atherosclerosis [15], and we found that atherosclerosis can cause the increase of serum autoantibody level in the early stage of lesions through SEREX [26-30]. Based on this background, it is clear that there is a significant need for the identification of sensitive, specific, and novel biomarkers to early predicting of TIA and $\mathrm{Cl}$. In the present study, our goal was to identify autoantibodies associated with TIA and CI by SEREX, which could be used as molecular predicted biomarkers to reflect the status of disease.

\section{Methods}

\section{Serum of patients and healthy donors (HDs)}

We collected serum samples from HDs and patients diagnosed with TIA and $\mathrm{Cl}$ caused by atherosclerotic vulnerable plaque [31, 32]. HDs were selected from individuals who did not have a history of TIA and Cl, 
including acute-phase cerebral infarction $(\mathrm{aCl})$ or old-cerebral infarction (oCl). Additionally, all of the selected HDs underwent medical checkups, including cerebral MRI. Subjects with autoimmune disease were excluded. A total of 19 TIA patients were randomly selected for immunological screening by SEREX.

In order to perform a comparison of the serum antibody levels, we set up four independent groups, which included 621 patients and $285 \mathrm{HDs}$. Of the 621 patients assigned to the validated disease groups, 92, 464 , and 65 suffered from $\mathrm{TIA}, \mathrm{aCl}$, and oCl, respectively. Table 1 shows the baseline characteristics of participants.

\section{Clinical data}

From patients' clinical records, we collected data regarding the risk factors for atherosclerosis, including the following: age, gender, HT, DM, hyperlipidemia, CHD, obesity, and smoking. HT was defined as a history of systolic blood pressure $>140 \mathrm{mmHg}$, diastolic blood pressure $>90 \mathrm{mmHg}$, or the use of antihypertensive agents. DM was defined as having previously diagnosed DM and/or DM treated with medication and/or fasting blood glucose $\geq 126 \mathrm{mg} / \mathrm{dL}$. Hyperlipidemia was defined as a history of total cholesterol $>220 \mathrm{mg} / \mathrm{dL}$, triglycerides $>150 \mathrm{mg} / \mathrm{dL}$, or use of lipid-lowering agents. CHD was defined as a history of myocardial infarction or angina pectoris. Patients were considered as smokers if they either smoked during the study period or had a history of smoking. Finally, obesity was defined as BMI $\geq 25$ $\mathrm{kg} / \mathrm{m}^{2}$. Additionally, we collected the participants' serum routine examination results, including blood routine, serum biochemistry, blood electrolytes, etc.

\section{Screening by expression cloning and identified antigens of sequence analysis}

In order to screen for clones that were immunoreactive against serum of patients with TIA, we used a commercially available human aortic endothelial cell cDNA library (Uni-ZAP XR Premade Library, Stratagene, La Jolla, CA). Escherichia coli (E. coli) XL1-Blue MRF囚 was infected with Uni-ZAP XR phage. For details, please refer to our previously published improved version of the immunoscreening method $[18,26,30,33,34]$.

We converted the monoclonalized phage cDNA clones to pBluescript phagemids by in vitro excision using ExAssist helper phage (Stratagene). Plasmid DNA was obtained from the E. coli SOLR strains transformed by the phagemids. Following sequencing of inserted cDNAs, homologous analysis was performed using a public database provided by the National Center for Biotechnology Information (https://blast.ncbi.nlm.nih.gov/Blast.cgi).

\section{Purification of recombinant candidate proteins}


We constructed expression plasmids of glutathione-S-transferase (GST)-fused proteins by recombining the $\mathrm{CDNA}$ sequences into pGEX-4T vectors and transfected it into $E$. coli $\mathrm{BL}-21$, as previously described [6, $17,21,33,34]$.

Transformed E. coli BL-21 cells containing pGEX-4T-2 clones were cultured. Subsequently, cell lysates were centrifuged and the GST fusion recombinant proteins recovered in the supernatant fraction were directly affinity purified by glutathione-Sepharose column chromatography (GE Healthcare Life Sciences), according to the manufacturer's and our previous instructions $[26,28,30]$. We dissolved the precipitates containing recombinant proteins in $8 \mathrm{M}$ urea in TED buffer [50 mM Tris-HCl (pH 8.0), $1 \mathrm{mM}$ EDTA, and 1 $\mathrm{mM}$ dithiothreitol]. Subsequently, we performed stepwise dialysis against 4 and $2 \mathrm{M}$ urea in TED buffer for every hour and samples were then dialyzed against TED buffer. We purified the recombinant proteins recovered in the supernatant using glutathione-Sepharose, as described above [26-30].

\section{Western blotting}

GST, GST-ALDOA, and GST-FH proteins $(0.3 \mu \mathrm{g})$ were electrophoresed through SDS-polyacrylamide gel followed by Western blotting. To this end, we used anti-GST (goat) or 1:5000-diluted serum from patients with TIA and $\mathrm{Cl}$ (\#350, and \#692). Proteins were then incubated with horseradish peroxidase-conjugated secondary antibody, as previously described $[30,33,35,36]$.

\section{Amplified luminescent proximity homogeneous assay-linked immunosorbent assay (AlphaLISA) of antibody biomarkers}

AlphaLISA was applied to the quantitative measurement of serum antibodies against the purified proteins. Prepare the sample mixture to be tested according to the instructions and our previous experience [27, 30,34]. The mixture was then incubated for 14 day at room temperature in the dark. Reading of the chemical emission was performed on an EnSpire Alpha microplate reader (Perkin Elmer). We calculated specific reactions by subtracting the Alpha values (Alpha counts) of the GST control from those of GST fusion proteins.

\section{Nested case-control study}

The Japan Public Health Center-based prospective Study (JPHC) $[37,38]$ conducted a baseline survey for 140,000 registered residents aged 40-69 years within 11 public health center areas nationwide between 1991 and 1993. Five- and 10-year follow-up surveys were conducted to update information on lifestyle habits and health conditions. In total, 60,000 participants provided blood samples on at least one of the two sampling times, and 23,000 on both. The subjects have been followed for vital status and the 
occurrence of cancer and other diseases. As of December 2011, 24,000 deaths have been documented, as well as 17,000 cases of cancer, 6,000 cases of stroke and 1,100 cases of myocardial infarction. Randomly selected 202 patients who had stroke (atherosclerosis-related) but no other diseases as the case and the 202 HDs served as the control during the follow-up in 2008 from JPHC. The nested casecohort study was performed using the above AlphaLISA detection, and the antibody levels were measured in cases and controls with matching age, gender, and area.

\section{Statistical analyses}

We compared differences in the Alpha values between two groups by using Student's $t$-test and MannWhitney $U$ test. Additionally, we determined the correlation between Alpha values and clinical case data using Spearman's correlation analysis. In order to identify the set of variables that could be used to classify participants according to positive history for ischemic stroke, univariate and multivariate logistic regression analyses were used. Conditional logistic regression model was used to estimate the odds ratios (ORs) for cerebral infarction compared to the antibody levels of ALDOA and FH in the nested casecontrol study. We assessed the predictive values of markers for diseases by receiver operating characteristic (ROC) analysis. Additionally, the cutoff values were set to maximize the sum of sensitivity and specificity. All tests were two-tailed. We considered as statistically significant $P<0.05$. All statistical analyses were performed using either the SPSS 13.0 software (SPSS Inc., Chicago, IL) or GraphPad Prism 5 (GraphPad Software, La Jolla, CA).

\section{Results}

\section{Identification of ALDOA and FH as antigens recognized by serum of patients with TIA}

We observed two independent clones in the serum of 19 TIA patients by expression cloning (Fig. 1). Specifically, we found a sequence homology with aldolase, fructose-bisphosphate A (ALDOA) (Accession number: NM_184041) and fumarate hydratase (FH) (Accession number: NM_000143), respectively. The region between amino acids 70 and 469 of ALDOA was obtained as a pBluescript II clone and then recombined into a pGEX-4T-2 expression vector. Similarly, the cloned region between amino acids 1 and 185 of $\mathrm{FH}$ was recombined into PGEX-4T-2 vectors. Recombinant ALDOA and FH proteins were expressed in $E$. coli as GST fusion proteins. They were subsequently purified by affinity chromatography using glutathione-Sepharose.

\section{Presence of serum antibodies was confirmed by Western blotting}

We aimed at confirming the presence of anti-ALDOA (ALDOA-Abs) and anti-FH (FH-Abs) antibodies in serum. To this end, Western blotting was performed using serum obtained from TIA and $\mathrm{Cl}$ patients. Using an anti-GST antibody, GST- ALDOA, GST- FH, and GST proteins were recognized as reactions of 65- 
kDa, 67-kDa, and 28-kDa proteins, respectively (Fig. 2). On the contrary, GST-ALDOA and/or GST-FH, but not GST, reacted with serum antibodies of patients \#350 and \#692. Based on these findings, we suggest that most, if not all, of GST fusion antigen proteins' reactivity with serum antibodies may be due to antigen proteins rather than the GST domain. In the present study, specific reactions against ALDOA or FH proteins were estimated by antibody levels toward GST-tagged antigen proteins subtracted the levels toward GST.

\section{Levels of ALDOA-Abs and FH-Abs are increased in patients with TIA and CI}

In order to quantitatively analyze ALDOA-Ab and FH-Ab levels in serum, AlphaLISA was used. To this end, we examined the serum of HDs and patients with $\mathrm{TIA}, \mathrm{aCl}$ or oCl. The Alpha counts represent the luminescent photon counts corresponding to the antibody levels. Our results showed that the levels of ALDOA-Abs and FH-Abs in the three ischemic cerebrovascular diseases (i.e., $\mathrm{TIA}, \mathrm{aCl}$, and oCl) were significantly higher compared with $\mathrm{HDs}(P<0.05)$ (Table 2). Furthermore, we observed no significant differences in the Alpha counts among patients with the three ischemic cerebrovascular diseases (Fig. 3). Therefore, ALDOA-Ab and FH-Ab levels may be closely related to ischemic cerebrovascular diseases, but not the disease type.

We performed the ROC analysis to evaluate the ability of these markers to detect $\mathrm{TIA}, \mathrm{aCl}$, and $\mathrm{OCl}$. The areas under the curve (AUC) of ALDOA-Abs and FH-Abs for TIA were 0.63 [95\% confidence interval (CI): $0.56-0.69$ ] (Fig. 4a) and 0.63 (95\% Cl: $0.56-0.70$ ) (Fig. 4d), respectively. While the AUC for aCl were 0.63 (95\% Cl: $0.60-0.67$ ) (Fig. 4b) and 0.63 (95\% Cl: $0.59-0.67)$ (Fig. 4e), respectively. Additionally, the AUC for oCl were 0.62 (95\% Cl: $0.54-0.70)$ (Fig. 4c) and 0.67 (95\% Cl: $0.60-0.75)$ (Fig. 4f). At a cutoff value of ALDOA-Ab levels of 14,869, the antibody level's sensitivity and specificity for TIA diagnosis were $69.57 \%$ and $54.74 \%$, respectively (Fig. $4 a$ ). Such levels were similar to those for aCl diagnosis $(69.40 \%$ and $51.58 \%$, respectively) (Fig. 4b). Furthermore, sensitivity and specificity for FH-Abs are shown in Fig. $4 d, 4 e$, and $4 f$.

\section{Association between TIA and clinical parameters including ALDOA-Ab and FH-Ab levels}

Results of univariate and multivariate logistic regression analyses are shown in Table 3. Using the cutoff value of 14,869 and 2,849, respectively, univariate logistic regression analysis revealed that the elevated ALDOA-Ab (OR: 2.91, 95\% Cl: $1.76-4.83, P<0.0001)$ and FH-Ab (OR: 2.88, 95\% Cl: $1.78-4.67, P<$ 0.0001 ) levels were associated with the increased risk of TIA, respectively. We included the univariate $P<$ 0.05 into the multivariate analysis factors. The multivariate logistic regression analysis revealed that elevated ALDOA-Ab (OR: 2.46, 95\% Cl: 1.31 -4.62, $P=0.0050)$ and FH-Ab (OR: 2.49, 95\% Cl: $1.35-4.63$, $P=0.0037)$ levels were independent predictors of TIA, respectively. The predictive values of ALDOA-Abs and FH-Abs for TIA were similar to that of HT which is a typical risk factor of TIA. Specifically, these 
include the following: age (OR: 6.04, 95\% Cl: 3.15 - 11.58, $P<0.0001)$ ) HT (OR: 2.97, 95\% Cl: $1.61-5.45$, $P=0.0005)$; and DM (OR: 5.31, 95\% Cl: $2.05-13.79, P=0.0006)$.

\section{Elevated positive prediction values by combination of ALDOA-Abs, FH-Abs, and clinical risk factors}

Next, we calculated the positive rates of 92 patients with TIA and 285 HDs including the conventional risk factors, age, HT, and DM. We used the cutoff values of ALDOA-Abs and FH-Abs to detect TIA, 14,869 and 2,849, respectively, as mentioned above. Positive predictive values (PPVs) of age, $\mathrm{HT}$, and DM alone were 48.0\%, 51.3\%, and 71.1\%, respectively (Table 4). On the contrary, PPVs of ALDOA-Abs combined with age, $\mathrm{HT}$, and DM increased to $63.1 \%, 63.5 \%$, and $91.3 \%$, respectively. Similarly, PPVs of FH-Abs combined with age, $\mathrm{HT}$, and DM were $61.9 \%, 56.9 \%$, and $94.1 \%$, respectively. Furthermore, PPVs with the combination of HT, DM, and ALDOA-Abs or age, DM, and FH-Abs reached up to $100 \%$.

\section{Japan Public Health Center (JPHC) cohort analysis}

The above logistic regression analysis proved that ALDOA-Abs and FH-Abs are independent early warning risk factors for TIA, which is one of prodromal stages of $\mathrm{Cl}$. To further validate their association with $\mathrm{Cl}$, we conducted a prospective case-control study nested within the JPHC-based prospective study (the interference of age, sex and area were excluded). ALDOA-Ab and FH-Ab levels were divided into four quartiles. We found that the ORs $(95 \% \mathrm{Cls})$ were $2.38(1.24-4.55)$ and $2.50(1.26-4.96)$ for individuals with the second and highest quartiles of antibody level, respectively, compared with the lowest quartile (Table 5). Additionally, we observed that FH-Ab levels were also positively associated with the risk of aCl. Specifically, we observed that the ORs ( $95 \%$ Cls) were $2.17(1.20-3.92)$ and $2.60(1.41-4.80)$, for individuals with the third and highest quartiles of antibody level, respectively. These results indicate that ALDOA-Abs and FH-Abs are useful markers in predicting the onset of aCl.

\section{Association between ALDOA-Abs and FH-Abs and clinical parameters}

We then examined the correlation between serum ALDOA-Ab and FH-Ab levels and sex, other diseases, lifestyle, and obesity (Table 6). The ALDOA-Ab levels were well associated with blood pressure $(P=$ $0.0022), \mathrm{CHD}(P=0.0400)$ and habitual smoking $(P<0.0001)$, but not with sex, $\mathrm{DM}, \mathrm{HL}$, alcohol intake, or obesity. FH antibody levels showed similar correlation as that of ALDOA except significant correlation with $\mathrm{DM}(P=0.0183)$ and less correlation with smoking habit $(P=0.0566)$.

Next, correlation between antibody levels and other clinical parameters was examined with Spearman correlation analysis. The levels of both AODOA-Abs and FH-Abs were significantly correlated with age, blood pressure, maximum intima-media thickness (max IMT), and blood sugar (Table 7). Because max 
IMT is one of indices of atherosclerosis, both ALDOA-Abs and FH-Abs could reflect the degree of atherosclerosis. Consistently with the results of Table 6, DM-related blood sugar was more closely related to $\mathrm{FH}-\mathrm{Ab}$ levels than ALDOA-Abs. On the other hand, the antibody levels were inversely correlated with albumin/globulin ratio, cholinesterase, total protein, albumin, total cholesterol, and red blood cell number.

\section{Discussion}

The two antigens, ALDOA and $\mathrm{FH}$, were found following serological identification of antigens by means of recombinant cDNA expression cloning. Serum IgG antibodies in TIA patients further recognized. Additionally, we confirmed by Western blotting the presence of antibodies against ALDOA and FH in the patients' serum (Fig. 2). Furthermore, we evaluated the antibody levels by means of AlphaLISA. AlphaLISA also allowed us to compare the levels between patients and HDs. Our results show that, compared with HDs, the antibody levels of anti-ALDOA (ALDOA-Abs) and anti-FH (FH-Abs) were significantly elevated in patients with $\mathrm{TIA}, \mathrm{aCl}$, or oCl (Fig. 3). We gathered additional confirmation that these antibodies are independent predictors (the interference of age, sex and area were excluded) of TIA by clinical statistical analysis (Table 3). Of note, TIA has a tendency to develop into aCl and is a clear risk factor of $\mathrm{aCl}$ [39]. As an independent early warning risk factor for TIA, these elevated antibody levels may also be predictive markers of aCl. Therefore, further confirmation was obtained by statistical analysis of prospective case-control studies nested in large community-based samples (Table 5).

Earlier studies had shown that ALDOA, also known as fructose-bisphosphate aldolase A, represented one of the glycolytic enzymes that catalyze the reversible conversion of fructose-1, 6-bisphosphate to glyceraldehyde-3-phosphate and dihydroxyacetone phosphate [40]. ALDOA is widely distributed in whole body tissues. As a catalytic enzyme, ALDOA represents one of the key enzymes in the glycolysis process. Of note, it plays a role in the hypoxia responses regulating both glucose and energy metabolism and can be served as hypoxia biomarkers [41]. Ischemic stroke represents a typical atherosclerosis-related disease. Its basic pathophysiological feature is represented by local tissue hypoxia. Studies have shown that ALDOA is a hypoxia-inducible gene expression product [42]. When brain tissue undergoes ischemia or hypoxia, both glucose uptake and metabolism are stimulated to compensate for the reduction in energy production by inducing overexpression of ALDOA [43]. Hypoxia-inducible factor $1 \mathrm{a}(\mathrm{HIF-1a})$ is a transcription factor which is sensitive to hypoxia-inducible genes. HIF-1a up-regulates ALDOA's expression in hypoxic cells [44], thereby enhancing its glycolysis metabolism. A previous study by Chang et al. proved that overexpression of ALDOA upregulated the expression of matrix metalloproteinase (MMP) 9 via HIF-1a [45]. These results were in line with our previous study [27] where we found an increased specificity of anti-MMP1 antibodies in the serum of TIA patients. MMPs can degrade the main components of the vascular extracellular matrix, which is an important factor that is responsible for the induction of atherosclerosis. An intimate relationship between ALDOA and MMPs suggests that ALDOA's overexpression may not only be a sequential pathological process in TIA's development, but it may also be related to TIA's initiation and deterioration. Of note, we observed that the ALDOA-Ab levels were well associated with $\mathrm{HT}, \mathrm{CHD}$ and habitual smoking, but not with sex, DM, HL, alcohol abuse and obesity (Table 6). ALDOA-Abs are associated with max-IMT, metabolic disturbance (e.g., blood sugar, total 
cholesterol, total protein, etc.), and inflammation (e.g., white blood cell count, C-reactive protein, etc.) (Table 7). These results suggest that the serum ALDOA-Ab marker can discriminate HT-induced atherosclerotic TIA and $\mathrm{aCl}$.

$\mathrm{FH}$ is a key enzyme involved in the tricarboxylic acid (TCA) cycle. It can reversibly catalyze the conversion of fumaric acid to L-malate in the cells [46]. A primary function of the TCA cycle is the oxidation of pyruvate, supplied by the glycolytic pathway, with the goal of producing energy. In addition to its classical metabolic-related functions, $\mathrm{FH}$ has other non-metabolic-related functions under the stimulation of cells [47]. Reports have associated FH with tumorigenesis, specifically by altering the gene expression and configuration of tumor cells [48]. In an earlier study, Xiao et al. found that FH could antagonize aketoglutarate-dependent demethylase through its metabolite fumarate, thereby affecting histone methylation [49]. In addition, Wang et al. also showed that FH exhibited adenosine monophosphateactivated protein kinase-mediated phosphorylation in the absence of glucose or hypoxia, which inhibited histone's demethylation by lysine-specific demethylase 2A [50]. FH inhibits histone methylation by reducing the physiological activity of vascular endothelial growth factor (VEGF) [51]. This, in turn, affects the repair and remodeling of vascular endothelium following atherosclerosis. It is noteworthy that abnormal histone methylation is responsible for significant gene expression changes, including VEGF. It has been shown that $\mathrm{FH}$ plays an important regulatory role in atherosclerosis occurrence and development [52], which is consistent with our finding that FH-Ab levels in TIA and ischemic stroke patients are significantly higher than those in HDs (Fig. 3).

Since TIA is one of prodromal stages of aCl, ALDOA-Abs and FH-Abs can be used as risk predictors. To examine this possibility, we conducted a case-control study nested within the JPHC-based prospective study. ALDOA and FH's antibody levels were measured in 202 cases of incident cerebral infarction developed in patients of the cohort between the baseline and 2008, and in 202 controls with matching age, sex, and area. In order to estimate the levels of ALDOA and FH for aCl (associated with atherosclerosis), we used a conditional logistic regression model. Our results showed that ALDOA and FH's antibody levels were positively and strongly associated with the risk of aCl (Table 5). As a consequence, we believe that such antibody markers can be applied to predictive diagnosis rather than simple risk evaluation.

Although PPVs of ALDOA-Abs and FH-Abs for TIA were $69.57 \%$ and $55.43 \%$, respectively (Fig. 4), they increased by combination with conventional risk factors such as age, $\mathrm{HT}$, and DM (Table 4). Especially, $100 \%$ of PPV was attained by combination with ALDOA-Abs, HT, and DM or FH-Abs, age, and DM. Thus, antibody markers combined with clinical risk factors improve the ability to predict TIA, which suggests that these combination is applicable to the early prediction of $\mathrm{aCl}$. The levels of ALDOA-Abs and FH-Abs were correlated with CHD, HT, habitual smoking (ALDOA-Ab), DM (FH-DM) (Table 6), age, max IMT, Creactive protein, blood sugar (Table 7). Max IMT is one of typical indecies of atherosclerosis, and CHD and DM are atherosclerosis-related diseases. HT, habitual smoking, age, C-reactive protein, and blood sugar are risk factors for atherosclerosis. Consequently, ALDOA-Abs and FH-Abs are biomarkers for 
atherosclerotic ischemic stroke. The large-scale JPHC cohort analysis showed these antibody markers were useful to predict the onset of $\mathrm{aCl}$.

\section{Conclusions}

The antibody levels against ALDOA and FH were significantly higher in patients with $\mathrm{TIA}$ or aCl than in HDs. These antibody markers can be applicable to predict TIA and pre-onset diagnosis of aCl which are induced by atherosclerosis.

\section{Abbreviations}

TIA: Transient ischemic attack; aCl: Acute cerebral infarction; HD: Healthy donor; oCl: Old cerebral infarction; HT: Hypertension; DM: Diabetes mellitus; CHD: Coronary heart disease; BMI: Body mass index; SEREX: Serological identification of antigens by recombinant CDNA expression cloning; $E$. coli: Escherichia coli; GST: Glutathione-S-transferase; AlphaLISA: Amplified luminescent proximity homogeneous assay-linked immunosorbent assay; JPHC: The Japan Public Health Center-based prospective Study; OR: odds ratio; ROC: receiver operating characteristic; ALDOA: Aldolase A, fructosebisphosphate; ALDOA-Ab: anti-ALDOA antibody; FH: Fumarate hydratase; FH-Ab; anti-FH antibody; 95\% Cl: 95\% confidence interval; PPV: Positive predictive value; max IMT: Maximum intima-media thickness; HIF-1a: Hypoxia-inducible factor 1a; MMP: Matrix metalloproteinase; VEGF: Vascular endothelial growth factor

\section{Declarations}

\section{Ethics approval and consent to participate}

This study was approved by the ethics committee of the Graduate School of Medicine, Chiba University. Our study was implemented in accordance with the ethical standards of the 1964 Declaration of Helsinki and its later amendments. The need for written informed consent was waived because of the retrospective nature of this study.

\section{Consent for publication}

Not applicable.

\section{Availability of data and materials}

The datasets used and/or analyzed during the current study are available from the corresponding author on reasonable request. 


\section{Competing interests}

This work was performed in collaboration with Fujikura Kasei Co., Ltd. Go Tomiyoshi, Rika Nakamura, Natsuko Shinmen, and Hideyuki Kuroda are employees of Fujikura Kasei Co., Ltd.

\section{Funding}

This work was supported in part by Natural Science Foundation of Guangdong Province, China (Grant NO: 2018A0303131003), Science and Technology Program of Guangzhou, China (Grant NO:

201707010449), Project of Traditional Chinese Medicine Bureau of Guangdong Province, China (Grant NO: 20181073), Medical Science and Technology Research Fund of Guangdong Province, China (Grant NO: A2018249), and a research grant from the Japan Agency for Medical Research and Development (AMED) of Japan (Practical Research Project for Life-Style related Diseases including Cardiovascular Diseases and Diabetes Mellitus), JSPS KAKENHI Grant Number 20K17953, 19K09451, 17K19810, 17K16626, 19K08596, 18K07387, Toka-Donghua Educational and Cultural Exchange Foundation, and Setsuro Fujii Memorial of Medical Sciences and The Osaka Foundation for Promotion of Fundamental Medical Research.

JPHC Study was supported by National Cancer Center Research and Development Fund (since 2011) and a Grant-in-Aid for Cancer Research from the Ministry of Health, Labour and Welfare of Japan (from 1989 to 2010).

\section{Authors' contributions}

$H W, E K, Y I, K G, A X$, and TH conceived and designed the experiments; HW, XMZ, YY, KS, GT, and RN performed the experiments; HW, HL, HI, MS, KY, NSa, ST, AAd, TMat, and TMac analyzed and interpreted the data; SM, IK, TW, AAo, HT, KK, HS, NSh, and HK contributed reagents, materials, analysis tools or data; $\mathrm{HW}, \mathrm{HL}, \mathrm{EK}, \mathrm{YI}, \mathrm{KY}, \mathrm{NSa}$, and TH wrote the paper.

\section{Acknowledgements}

The authors would like to thank Prof. Masaki Takiguchi (Department of Biochemistry and Genetics, Graduate School of Medicine, Chiba University) for valuable discussion and suggestion.

\section{References}


1. Easton JD, Saver JL, Albers GW, Alberts MJ, Chaturvedi S, Feldmann E, et al. Definition and evaluation of transient ischemic attack: a scientific statement for healthcare professionals from the American Heart Association/American Stroke Association Stroke Council; Council on Cardiovascular Surgery and Anesthesia; Council on Cardiovascular Radiology and Intervention; Council on Cardiovascular Nursing; and the Interdisciplinary Council on Peripheral Vascular Disease. The American Academy of Neurology affirms the value of this statement as an educational tool for neurologists. Stroke. 2009;40(6):2276-93. doi: 10.1161/STROKEAHA.108.192218.

2. Sacco RL, Kasner SE, Broderick JP, Caplan LR, Connors J, Culebras A, et al. An updated definition of stroke for the 21 st century: a statement for healthcare professionals from the American Heart Association/American Stroke Association. Stroke. 2013;44(7):2064-89. doi:

10.1161/STR.0b013e318296aeca.

3. Lisabeth LD, Ireland JK, Risser JM, Brown DL, Smith MA, Garcia NM, Morgenstern LB. Stroke risk after transient ischemic attack in a population-based setting. Stroke. 2004;35(8):1842-6. doi: 10.1161/01.STR.0000134416.89389.9d.

4. Kleindorfer D, Panagos P, Pancioli A, Khoury J, Kissela B, Woo D, et al. Incidence and short-term prognosis of transient ischemic attack in a population-based study. Stroke. 2005;36(4):720-3. doi: 10.1161/01.STR.0000158917.59233.b7.

5. Kernan WN, Ovbiagele B, Black HR, Bravata DM, Chimowitz MI, Ezekowitz MD, et al. Guidelines for the prevention of stroke in patients with stroke and transient ischemic attack: a guideline for healthcare professionals from the American Heart Association/American Stroke Association. Stroke. 2014;45(7):2160-236. doi: 10.1161/STR.0000000000000024.

6. Bonow RH, Witt CE, Mosher BP, Mossa-Basha M, Vavilala MS, Rivara FP, et al. Transcranial Doppler microemboli monitoring for stroke risk stratification in blunt cerebrovascular injury. Crit Care Med. 2017;45(10):e1011-7. doi: 10.1097/CCM.0000000000002549.

7. Coutts SB, Modi J, Patel SK, Demchuk AM, Goyal M, Hill MD, et al. CT/CT angiography and MRI findings predict recurrent stroke after transient ischemic attack and minor stroke: results of the prospective CATCH study. Stroke. 2012;43(4):1013-7. doi: 10.1161/STROKEAHA.111.637421.

8. Wolpert S, Caplan LR. Current role of cerebral angiography in the diagnosis of cerebrovascular diseases. AJR Am J Roentgenol. 1992;159(1):191-7. doi: 10.2214/ajr.159.1.1609697.

9. Stemme S, Faber B, Holm J, Wiklund O, Witztum JL, Hansson GK. T lymphocytes from human atherosclerotic plaques recognize oxidized low density lipoprotein. Proc Natl Acad Sci USA. 1995;92(9):3893-7. doi: 10.1073/pnas.92.9.3893.

10. Homocysteine Studies Collaboration. Homocysteine and risk of ischemic heart disease and stroke: a meta-analysis. Jama. 2002;288(16):2015-22. doi: 10.1001/jama.288.16.2015.

11. Nambi V, Hoogeveen RC, Chambless L, Hu Y, Bang H, Coresh J, et al. Lipoprotein-associated phospholipase A2 and high-sensitivity C-reactive protein improve the stratification of ischemic stroke risk in the Atherosclerosis Risk in Communities (ARIC) study. Stroke. 2009;40(2):376-81. doi: 10.1161/STROKEAHA.107.513259. 
12. Kramer J, Harcos P, Prohászka Z, Horváth L, Karádi I, Singh M, et al. Frequencies of certain complement protein alleles and serum levels of anti-heat-shock protein antibodies in cerebrovascular diseases. Stroke. 2000;31(11):2648-52. doi: 10.1161/01.str.31.11.2648

13. O'Donnell MJ, Xavier D, Liu L, Zhang H, Chin SL, Rao-Melacini P, et al. Risk factors for ischaemic and intracerebral haemorrhagic stroke in 22 countries (the INTERSTROKE study): a case-control study. Lancet. 2010;376(9735):112-23. doi: 10.1016/S0140-6736(10)60834-3.

14. Dolmans LS, Rutten FH, El Bartelink ML, Seppenwoolde G, van Delft S, Kappelle LJ, Hoes AW. Serum biomarkers for the early diagnosis of TIA: The MIND-TIA study protocol. BMC Neurol. 2015;15:119. doi: 10.1186/s12883-015-0388-z.

15. Amarenco P, Cohen A, Tzourio C, Bertrand B, Hommel M, Besson G, et al. Atherosclerotic disease of the aortic arch and the risk of ischemic stroke. New Engl J Med. 1994;331(22):1474-9. doi: 10.1056/NEJM199412013312202

16. Matsuura E, Atzeni F, Sarzi-Puttini P, Turiel M, Lopez LR, Nurmohamed MT. Is atherosclerosis an autoimmune disease? BMC Med. 2014;12:47. doi: 10.1186/1741-7015-12-47.

17. Matsuura E, Kobayashi K, Lopez LR. Atherosclerosis in autoimmune diseases. Curr Rheumatol Rep. 2009;11(1):61-9. doi: 10.1007/s11926-009-0009-1

18. Hiwasa T, Zhang XM, Kimura R, Ohno M, Chen PM, Nishi E, et al. Elevated Adiponectin Antibody Levels in Serum of Patients with Atherosclerosis-Related Coronary Artery Disease, Cerebral Infarction and Diabetes Mellitus. J Circ Biomark. 2016;5:8. doi: 10.5772/63218.

19. Sahin U, Türeci O, Schmitt H, Cochlovius B, Johannes T, Schmits R, et al. Human neoplasms elicit multiple specific immune responses in the autologous host. Proc Natl Acad Sci U S A. 1995;92(25):11810-3. doi: 10.1073/pnas.92.25.11810.

20. Türeci O, Usener D, Schneider S, Sahin U. Identification of tumor-associated autoantigens with SEREX. Methods Mol Med. 2005;109:137-54. doi: 10.1385/1-59259-862-5:137.

21. Scanlan MJ. Identification of human tumor antigens by serological analysis of recombinant cDNA expression libraries (SEREX). Curr Protoc Immunol. 2005;Chapter 20:Unit 20.7. doi:

10.1002/0471142735.im2007s65.

22. Lim Y, Lee DY, Lee S, Park SY, Kim J, Cho B, et al. Identification of autoantibodies associated with systemic lupus erythematosus. Biochem Biophys Res Commun. 2002;295(1):119-24. doi: 10.1016/s0006-291x(02)00637-x.

23. Kaneko M, Ono T, Matsubara T, Yamamoto Y, Ikeda H, Yoshiki T, et al. Serological identification of endothelial antigens predominantly recognized in Kawasaki disease patients by recombinant expression cloning. Microbio immunol. 2004;48(9):703-11. doi: 10.1111/j.13480421.2004.tb03472.x.

24. Lu Y, Ye P, Chen SL, Tan EM, Chan EK. Identification of kinectin as a novel Behçet's disease autoantigen. Arthritis Res Ther. 2005;7(5):R1133-9. doi: 10.1186/ar1798.

25. Muto M, Mori M, Hiwasa T, Takiguchi M, Iwadate Y, Uzawa A, et al. Novel serum autoantibodies against talin 1 in multiple sclerosis: Possible pathogenetic roles of the antibodies. J Neuroimmunol. 
2015;284:30-6. doi: 10.1016/j.jneuroim.2015.05.005.

26. Machida T, Kubota M, Kobayashi E, Iwadate Y, Saeki N, Yamaura A, et al. Identification of strokeassociated-antigens via screening of recombinant proteins from the human expression cDNA library (SEREX). J Transl Med. 2015;13(1):71. doi: 10.1186/s12967-015-0393-4.

27. Wang $H$, Zhang XM, Tomiyoshi G, Nakamura R, Shinmen N, Kuroda $H$, et al. Association of serum levels of antibodies against MMP1, CBX1, and CBX5 with transient ischemic attack and cerebral infarction. Oncotarget. 2017;9(5):5600-13. doi: 10.18632/oncotarget.23789.

28. Hiwasa T, Machida T, Zhang XM, Kimura R, Wang H, Iwase $K$, et al. Elevated levels of autoantibodies against ATP2B4 and BMP-1 in sera of patients with atherosclerosis-related diseases. Immunome Res. 2015;11(2): 097. doi:10.4172/17457580.1000097.

29. Hiwasa T, Zhang XM, Kimura R, Machida T, Kitamura K, Yamazoe R, et al. Association of serum antibody levels against TUBB2C with diabetes and cerebral infarction. Gratis J Biomed Sci. 2015;1(2):49-63. doi: 10.18314/gjbs.v1i2.27.

30. Hiwasa T, Tomiyoshi G, Nakamura R, Shinmen N, Kuroda H, Kunimatsu M, et al. Serum SH3BP5specific antibody level is a biomarker of atherosclerosis. Immunome Res. 2017;13(2). doi: 10.4172/17457580.1000132.

31. Naghavi M, Libby P, Falk E, Casscells SW, Litovsky S, Rumberger J, et al. From vulnerable plaque to vulnerable patient: a call for new definitions and risk assessment strategies: Part I. Circulation. 2003;108(14):1664-72. doi: 10.1161/01.CIR.0000087480.94275.97.

32. Adams HP Jr, Bendixen BH, Kappelle LJ, Biller J, Love BB, Gordon DL, et al. Classification of subtype of acute ischemic stroke. Definitions for use in a multicenter clinical trial. TOAST. Trial of Org 10172 in Acute Stroke Treatment. Stroke. 1993;24(1):35-41. doi: 10.1161/01.str.24.1.35.

33. Nakamura R, Tomiyoshi G, Shinmen N, Kuroda H, Kudo T, Doi H, et al. An anti-deoxyhypusine synthase antibody as a marker of atherosclerosis-related cerebral infarction, myocardial infarction, diabetes mellitus, and chronic kidney disease. SM Atheroscler J. 2017;1(1):1001.

34. Zhang XM, Wang H, Mine S, Takemoto M, Yokote $K$, Kitamura $K$, et al. Association of serum antiprolylcarboxypeptidase antibody marker with atherosclerotic diseases accompanied by hypertension. J Mol Biomark Diagn. 2017;8(5):361. doi: 10.4172/2155-9929.1000361.

35. Nakashima K, Shimada H, Ochiai T, Kuboshima M, Kuroiwa N, Okazumi S, et al. Serological identification of TROP2 by recombinant CDNA expression cloning using sera of patients with esophageal squamous cell carcinoma. Int J Cancer. 2004;112(6):1029-35. doi: 10.1002/ijc.20517.

36. Adachi-Hayama M, Adachi A, Shinozaki N, Matsutani T, Hiwasa T, Takiguchi M, et al. Circulating antifilamin $\mathrm{C}$ autoantibody as a potential serum biomarker for low-grade gliomas. BMC Cancer. 2014;14(1):452. doi: 10.1186/1471-2407-14-452.

37. Tsugane S, Sawada N. The JPHC study: design and some findings on the typical Japanese diet. Jap J Clin Oncol. 2014;44(9):777-82. doi: 10.1093/jjco/hyu096.

38. Yamagishi K, Iso H, Kokubo Y, Saito I, Yatsuya H, Ishihara J, et al. Dietary intake of saturated fatty acids and incident stroke and coronary heart disease in Japanese communities: the JPHC Study. Eur 
Heart J. 2013;34(16):1225-32. doi: 10.1093/eurheartj/eht043.

39. Wu CM, McLaughlin K, Lorenzetti DL, Hill MD, Manns BJ, Ghali WA. Early risk of stroke after transient ischemic attack: a systematic review and meta-analysis. Arch Intern Med. 2007;167(22):2417-22. doi: 10.1001/archinte.167.22.2417.

40. Rottmann WH, Tolan DR, Penhoet EE. Complete amino acid sequence for human aldolase B derived from cDNA and genomic clones. Proc Natl Acad Sci U S A. 1984;81(9):2738-42. doi:10.1073/pnas.81.9.2738.

41. Zeng Y, Lv Y, Tao L, Ma J, Zhang H, Xu H, et al. G6PC3, ALDOA and CS induction accompanies mir122 down-regulation in the mechanical asphyxia and can serve as hypoxia biomarkers. Oncotarget. 2016;7(46):74526-36. doi: 10.18632/oncotarget.12931.

42. Kawai K, Uemura M, Munakata K, Takahashi H, Haraguchi N, Nishimura J, et al. Fructosebisphosphate aldolase $\mathrm{A}$ is a key regulator of hypoxic adaptation in colorectal cancer cells and involved in treatment resistance and poor prognosis. Int J Oncol. 2017;50(2):525-34. doi: 10.3892/ijo.2016.3814.

43. Semenza GL, Roth PH, Fang HM, Wang GL. Transcriptional regulation of genes encoding glycolytic enzymes by hypoxia-inducible factor 1. J Biol Chem. 1994;269(38):23757-63. doi: 10.1016/00928674(94)90283-6

44. Grandjean G, De Jong PR, James BP, Koh MY, Lemos R, Kingston J, et al. Definition of a novel feedforward mechanism for glycolysis-HIF1a signaling in hypoxic tumors highlights aldolase A as a therapeutic target. Cancer Res. 2016;76(14):4259-69. doi: 10.1158/0008-5472.CAN-16-0401.

45. Chang YC, Chan YC, Chang WM, Lin YF, Yang CJ, Su CY, et al. Feedback regulation of ALDOA activates the HIF-1a/MMP9 axis to promote lung cancer progression. Cancer Lett. 2017;403:28-36. doi: 10.1016/j.canlet.2017.06.001.

46. Yogev O, Yogev O, Singer E, Shaulian E, Goldberg M, Fox TD, Pines O. Fumarase: a mitochondrial metabolic enzyme and a cytosolic/nuclear component of the DNA damage response. PLoS Biol. 2010;8(3):e1000328. doi: 10.1371/journal.pbio.1000328.

47. Yang W, Xia Y, Hawke D, Li X, Liang J, Xing D, et al. PKM2 phosphorylates histone $\mathrm{H} 3$ and promotes gene transcription and tumorigenesis. Cell. 2012;150(4):685-96. doi: 10.1016/j.cell.2012.07.018.

48. Yang M, Soga T, Pollard PJ, Adam J. The emerging role of fumarate as an oncometabolite. Front Oncol. 2012;2:85. doi: 10.3389/fonc.2012.00085.

49. Xiao M, Yang H, Xu W, Ma S, Lin H, Zhu H, et al. Inhibition of a-KG-dependent histone and DNA demethylases by fumarate and succinate that are accumulated in mutations of $\mathrm{FH}$ and SDH tumor suppressors. Gene Dev. 2012;26(12):1326-38. doi: 10.1101/gad.191056.112.

50. Wang T, Yu Q, Li J, Hu B, Zhao Q, Ma C, et al. O-GlcNAcylation of fumarase maintains tumour growth under glucose deficiency. Nat Cell Biol. 2017;19(7):833-43. doi: 10.1038/ncb3562.

51. Huang T, Yuan GF, Zhang ZG, Zou ZQ, Li D. Cardiovascular pathogenesis in hyperhomocysteinemia. Asia Pac J Clin Nutr. 2008;17(1):8-16. doi: 10.6133/apjen.2008.17.1.02. 
52. Kim YR, Kim CS, Naqvi A, Kumar A, Kumar S, Hoffman TA, Irani K. Epigenetic upregulation of p66shc mediates low-density lipoprotein cholesterol-induced endothelial cell dysfunction. Am J Physiol Heart Circ Physiol. 2012;303(2):H189-96. doi: 10.1152/ajpheart.01218.2011.

\section{Tables}

Table 1. Baseline characteristics of subjects enrolled in the study.

\begin{tabular}{|c|c|c|c|c|c|}
\hline & \multirow{3}{*}{$\begin{array}{c}\text { SEREX } \\
\text { TIA }^{\mathrm{a}} \\
(n=19)\end{array}$} & \multicolumn{4}{|c|}{ AlphaLISA } \\
\hline & & \multicolumn{3}{|c|}{ Stroke } & \multirow{3}{*}{$\begin{array}{c}\mathrm{HD} \\
(n=285)\end{array}$} \\
\hline & & TIA & $\mathrm{aCI}$ & oCI & \\
\hline & & $(n=92)$ & $(n=464)$ & $(n=65)$ & \\
\hline \multirow[t]{2}{*}{ Age } & $68.3 * * *$ & $70.2 * * *$ & $75.5^{* * * *}$ & $73.3^{* * * *}$ & 52.3 \\
\hline & $( \pm 10.2)$ & $( \pm 11.6)$ & $( \pm 11.5)$ & $( \pm 9.2)$ & $( \pm 11.7)$ \\
\hline \multirow[t]{2}{*}{ Male gender } & 16 & 55 & 271 & 48 & 188 \\
\hline & $(84.2 \%)$ & $(59.7 \%)$ & $(58.4 \%)$ & $(73.8 \%)$ & $(65.9 \%)$ \\
\hline \multirow[t]{2}{*}{$\mathrm{HT}$} & $13 * * *$ & $60 * * *$ & $335 * * *$ & $53 * * *$ & 57 \\
\hline & $(68.4 \%)$ & $(65.2 \%)$ & $(72.2 \%)$ & $(81.5 \%)$ & $(20.0 \%)$ \\
\hline \multirow[t]{3}{*}{$\mathrm{DM}$} & $3 * * *$ & $27 * * *$ & $125 * * *$ & $22 * * *$ & 11 \\
\hline & & (29.3\%) & (26.9\%) & (33.8\%) & (3.9\%) \\
\hline & $(15.8 \%)$ & & & & \\
\hline \multirow[t]{2}{*}{$\mathrm{HL}$} & 3 & $36 * * *$ & $122 * * *$ & $25 * * *$ & 40 \\
\hline & (15.8\%) & (39.1\%) & $(26.3 \%)$ & $(38.5 \%)$ & $(14.0 \%)$ \\
\hline \multirow[t]{2}{*}{ CHD } & $1 * * *$ & $5 * * *$ & $40 * * *$ & $2 * * *$ & 0 \\
\hline & $(5.2 \%)$ & $(5.4 \%)$ & $(8.6 \%)$ & (3.1\%) & \\
\hline \multirow[t]{2}{*}{ Obesity (BMI $\geq 25$ ) } & 10 & 30 & 127 & 11 & 88 \\
\hline & $(52.6 \%)$ & $(32.6 \%)$ & $(27.4 \%)$ & $(16.9 \%)$ & $(30.9 \%)$ \\
\hline \multirow[t]{2}{*}{ Smoking } & 12 & 43 & 228 & 33 & 132 \\
\hline & $(63.1 \%)$ & $(46.7 \%)$ & $(49.1 \%)$ & $(50.8 \%)$ & $(46.3 \%)$ \\
\hline
\end{tabular}

Data represents means ( \pm SD) for continuous data and $n(\%)$ for categorical data.

$\star \star \star ~ P<0.001$ vs. HD.

a TIA, transient ischemic attack; aCl, acute cerebral infarction; $\mathrm{HD}$, healthy donor; oCl, old cerebral infarction; $\mathrm{HT}$, hypertension; DM, diabetes mellitus; $\mathrm{HL}$, hyperlipidemia; $\mathrm{CHD}$, coronary heart disease; $\mathrm{BMI}$, body mass index.

Table 2. Comparison of serum antibody levels between $\mathrm{HDs}$ and patients with $\mathrm{TIA}$, aCl, or oCl examined by AlphaLISA. 


\begin{tabular}{|c|c|c|c|c|c|c|c|}
\hline \multicolumn{2}{|l|}{$\mathrm{HD}$} & \multicolumn{2}{|c|}{ TIA } & \multicolumn{2}{|c|}{$\mathrm{aCI}$} & \multicolumn{2}{|c|}{ oCI } \\
\hline ALDOA-Ab & FH-Ab & ALDOA-Ab & FH-Ab & ALDOA-Ab & FH-Ab & ALDOA-Ab & $\mathrm{FH}-\mathrm{Ab}$ \\
\hline 16,326 & 2,492 & 20,675 & 3,852 & 20,431 & 3,850 & 20,144 & 4,226 \\
\hline 10,410 & 2,367 & 12,464 & 3,765 & 10,564 & 3,699 & 10,633 & 3,112 \\
\hline 285 & 285 & 92 & 92 & 464 & 464 & 65 & 65 \\
\hline & & 0.0030 & 0.0015 & $<0.0001$ & $<0.0001$ & 0.0102 & $<0.0001$ \\
\hline
\end{tabular}

The average, SD, and the total sample number are presented for HDs and patients as well as $P$ values of statistical comparisons between HDs and patients. $P$ values less than 0.05 are marked in bold.

Table 3. Logistic regression of predictive factors for TIA ( $n=377$; no. of events $=92)$.

\begin{tabular}{|c|c|c|c|c|c|c|}
\hline & \multicolumn{3}{|c|}{ Univariate } & \multicolumn{3}{|c|}{ Multivariate } \\
\hline & $P$ & OR & $95 \% \mathrm{CI}^{\mathrm{a}}$ & $P$ & OR & $95 \% \mathrm{CI}$ \\
\hline Age ( $(60)$ & $<0.0001$ & 9.97 & $5.65-17.59$ & $<0.0001$ & 6.04 & $3.15-11.58$ \\
\hline Gender & 0.2304 & 1.34 & $0.83-2.17$ & & & \\
\hline HT & $<0.0001$ & 7.50 & $4.47-2.59$ & 0.0005 & 2.97 & $1.61-5.45$ \\
\hline DM & $<0.0001$ & 10.35 & $4.88-21.94$ & 0.0006 & 5.31 & $2.05-13.79$ \\
\hline HL & $<0.0001$ & 3.94 & $2.30-6.73$ & 0.0523 & 1.94 & $0.99-3.79$ \\
\hline CHD & 0.0132 & 8.13 & $1.55-42.66$ & 0.8917 & 1.14 & $0.17-7.77$ \\
\hline BMI ( ( 25) & 0.7768 & 1.08 & $0.65-1.80$ & & & \\
\hline Smoking & 0.9653 & 1.01 & $0.63-1.62$ & & & \\
\hline ALDOA-Ab ${ }^{a}$ & $<0.0001$ & 2.91 & $1.76-4.83$ & 0.0050 & 2.46 & $1.31-4.62$ \\
\hline $\mathrm{FH}-\mathrm{Ab} \mathrm{b}^{\mathrm{b}}$ & $<0.0001$ & 2.88 & $1.78-4.67$ & 0.0037 & 2.49 & $1.35-4.63$ \\
\hline
\end{tabular}

Cutoff values of ADOLA-Abs and FH-Abs were 14,869 and 2,849, respectively, based on ROC curve analysis.

OR values $>2.00$ are marked in bold.

a $95 \% \mathrm{Cl}, 95 \%$ confidence interval; OR, odds ratio.

Table 4. Validation of predictive factors for TIA ( $n=377$; number of events=92) 


\begin{tabular}{|c|c|c|c|c|c|c|c|c|}
\hline & & $\operatorname{Age}^{C}$ & $\mathrm{HT}$ & $\mathrm{DM}$ & $\begin{array}{l}\text { Age } \\
+\mathrm{HT}\end{array}$ & $\begin{array}{l}\text { Age } \\
+\mathrm{DM}\end{array}$ & $\mathrm{HT}+\mathrm{DM}$ & $\begin{array}{l}\text { Age } \\
+\mathrm{HT}+\mathrm{DM}\end{array}$ \\
\hline \multirow[t]{3}{*}{ Single risk } & $\begin{array}{l}\text { TIA } \\
(+)\end{array}$ & 73 & 60 & 27 & 53 & 25 & 21 & 21 \\
\hline & TIA (-) & 79 & 57 & 11 & 28 & 5 & 5 & 2 \\
\hline & $P P V^{d}$ & $48.0 \%$ & $51.3 \%$ & $71.1 \%$ & $65.4 \%$ & $83.3 \%$ & $80.8 \%$ & $91.3 \%$ \\
\hline \multirow[t]{3}{*}{ Single risk +ALDOA- $\mathrm{Ab}^{\mathrm{a}}$} & $\begin{array}{l}\text { TIA } \\
(+)\end{array}$ & 53 & 47 & 21 & 41 & 20 & 17 & 17 \\
\hline & TIA (-) & 31 & 27 & 2 & 12 & 1 & 0 & 0 \\
\hline & PPV & $63.1 \%$ & $63.5 \%$ & $91.3 \%$ & $77.4 \%$ & $95.2 \%$ & $100.0 \%$ & $100.0 \%$ \\
\hline \multirow[t]{3}{*}{ Single risk $+\mathrm{FH}-\mathrm{Ab}^{\mathrm{b}}$} & $\begin{array}{l}\text { TIA } \\
(+)\end{array}$ & 39 & 33 & 16 & 29 & 14 & 14 & 13 \\
\hline & TIA (-) & 24 & 25 & 1 & 12 & 0 & 1 & 0 \\
\hline & PPV & $61.9 \%$ & $56.9 \%$ & $94.1 \%$ & $70.7 \%$ & $100.0 \%$ & $93.3 \%$ & $100.0 \%$ \\
\hline \multirow[t]{3}{*}{$\begin{array}{l}\text { Single risk +ALDOA-Ab +FH- } \\
\mathrm{Ab}\end{array}$} & $\begin{array}{l}\text { TIA } \\
(+)\end{array}$ & 32 & 29 & 15 & 25 & 14 & 13 & 13 \\
\hline & TIA (-) & 11 & 14 & 0 & 7 & 0 & 0 & 0 \\
\hline & PPV & $74.4 \%$ & $67.4 \%$ & $100.0 \%$ & $78.1 \%$ & $100.0 \%$ & $100.0 \%$ & $100.0 \%$ \\
\hline
\end{tabular}

a ADOLA-Ab, elevated ADOLA-Ab levels, > 14,869.

b FH-Ab, elevated FH-Ab levels, > 2,849.

C Age, $\geq 60$.

d PPV, positive predictive value.

Table 5. Age and sex-matched, conditional odds ratios and 95\% confidence intervals of incident aCl according to antibody markers (202 cases and 202 controls).

\begin{tabular}{lccc}
\hline Antibody marker & & case / control & Matched OR (95\% CI) \\
\hline ALDOA-Abs & 1st & $30 / 50$ & 1.00 \\
& 2nd & $62 / 51$ & $\mathbf{2 . 3 8}(1.24-4.55)$ \\
& 3rd & $50 / 51$ & $1.95(1.00-3.82)$ \\
& 4th & $60 / 50$ & $\mathbf{2 . 5 0}(1.26-4.96)$ \\
\hline FH-Abs & 1st & $29 / 50$ & 1.00 \\
& 2nd & $40 / 51$ & $1.33(0.72-2.48)$ \\
& 3rd & $62 / 51$ & $\mathbf{2 . 1 7}(1.20-3.92)$ \\
& 4th & $71 / 50$ & $\mathbf{2 . 6 0}(1.41-4.80)$ \\
\hline
\end{tabular}

OR values $>2.00$ are marked in bold.

Table 6. Correlation analysis between serum antibody marker levels and sex, other diseases, lifestyle, and obesity. 


\begin{tabular}{|c|c|c|c|c|c|}
\hline \multirow[b]{2}{*}{ Sex } & & \multicolumn{2}{|c|}{ ALDOA-Ab } & \multicolumn{2}{|c|}{ FH-Ab } \\
\hline & & Male & Female & Male & Female \\
\hline Sample number & & 692 & 458 & 692 & 458 \\
\hline \multirow{2}{*}{ ALDOA-Ab level } & Average & 19,087 & 18,196 & 3,323 & 3,492 \\
\hline & $\mathrm{SD}$ & 11,046 & 10,456 & 3,258 & 3,630 \\
\hline$P$ value (vs Male) & & & 0.1941 & & 0.2563 \\
\hline $\mathrm{DM}$ & & $\mathrm{DM}(-)$ & $\mathrm{DM}(+)$ & $\mathrm{DM}(-)$ & $\mathrm{DM}(+)$ \\
\hline Sample number & & 926 & 219 & 926 & 219 \\
\hline \multirow[t]{2}{*}{ ALDOA-Ab level } & Average & 18,637 & 19,189 & 3,315 & 3,710 \\
\hline & SD & 11,045 & 9,902 & 3,425 & 3,349 \\
\hline$P$ value [vs DM (-)] & & & 0.1250 & & 0.0183 \\
\hline Blood pressure & & HT (-) & $\mathrm{HT}(+)$ & HT $(-)$ & $\mathrm{HT}(+)$ \\
\hline Sample number & & 505 & 640 & 505 & 640 \\
\hline \multirow[t]{2}{*}{ ALDOA-Ab level } & Average & 17,927 & 19,388 & 2,977 & 3,717 \\
\hline & $\mathrm{SD}$ & 11,037 & 10,635 & 2,985 & 3,685 \\
\hline$P$ value $[$ vs HT $(-)]$ & & & 0.0022 & & $<0.0001$ \\
\hline CHD & & CHD (-) & $\mathrm{CHD}(+)$ & CHD- & $\mathrm{CHD}+$ \\
\hline Sample number & & 1086 & 59 & 1086 & 59 \\
\hline \multirow[t]{2}{*}{ ALDOA-Ab level } & Average & 18,600 & 21,373 & 3,336 & 4,397 \\
\hline & $\mathrm{SD}$ & 10,685 & 13,087 & 3,351 & 4,302 \\
\hline$P$ value [vs CHD (-)] & & & 0.0400 & & 0.0268 \\
\hline Lipidemia & & HL (-) & $\mathrm{HL}(+)$ & HL $(-)$ & $\mathrm{HL}(+)$ \\
\hline Sample number & & 844 & 301 & 844 & 301 \\
\hline \multirow[t]{2}{*}{ ALDOA-Ab level } & Average & 18,871 & 18,384 & 3,514 & 3,045 \\
\hline & $\mathrm{SD}$ & 11,144 & 9,923 & 3,688 & 2,455 \\
\hline$P$ value $[$ vs HL $(-)]$ & & & 0.6244 & & 0.6545 \\
\hline Life style & & Non-smoker & Smoker & Non-smoker & Smoker \\
\hline Sample number & & 584 & 561 & 584 & 561 \\
\hline \multirow[t]{2}{*}{ ALDOA-Ab level } & Average & 17,371 & 20,158 & 3,282 & 3,494 \\
\hline & $\mathrm{SD}$ & 9,641 & 11,783 & 3,587 & 3,186 \\
\hline$P$ value (vs non-smoker) & & & $<0.0001$ & & 0.0566 \\
\hline Life style & & Alcohol (-) & Alcohol (+) & Alcohol (-) & Alcohol (+) \\
\hline Sample number & & 338 & 570 & 338 & 570 \\
\hline \multirow[t]{2}{*}{ ALDOA-Ab level } & Average & 17,928 & 19,507 & 3,528 & 3,466 \\
\hline & SD & 9,311 & 12,373 & 3,544 & 3,492 \\
\hline$P$ value [vs Alcohol (-)] & & & 0.0817 & & 0.8972 \\
\hline Obesity & & $\mathrm{BMI}<25$ & $\mathrm{BMI} \geq 25$ & $\mathrm{BMI}<25$ & $\mathrm{BMI} \geq 25$ \\
\hline Sample number & & 809 & 315 & 809 & 315 \\
\hline \multirow[t]{2}{*}{ ALDOA-Ab level } & Average & 18,911 & 18,568 & 3,577 & 2,992 \\
\hline & SD & 11,198 & 10,049 & 3,722 & 2,475 \\
\hline$P$ value (vs BMI < 25) & & & 0.8354 & & 0.0720 \\
\hline
\end{tabular}

The subjects were divided into two groups as follows: sex (male and female); presence $(+)$ or absence $(-)$ of complication of DM, HT, CHD or hyperlipidemia (HL), lifestyle factors (smoking and alcohol intake habits), and obesity. Antibody levels (alpha counts) were compared using the Mann-Whitney Utest. 
Sample numbers, averages and SDs of counts as well as $P$ values are shown. Significant correlations $(P$ $<0.05$ ) are marked in bold.

Table 7. Correlation analysis between serum antibody marker levels and the indices in $\mathrm{HDs}$ and $\mathrm{Cl}$ patients.

\begin{tabular}{|c|c|c|c|c|}
\hline & \multicolumn{2}{|c|}{ ALDOA } & \multicolumn{2}{|c|}{ FH4 } \\
\hline & $r$ value & $P$ value & $r$ value & $P$ value \\
\hline Age & 0.1973 & $<0.0001$ & 0.2369 & $<0.0001$ \\
\hline Blood pressure & 0.1574 & $<0.0001$ & 0.0919 & 0.0196 \\
\hline Max intima-media thickness & 0.2353 & $<0.0001$ & 0.2179 & $<0.0001$ \\
\hline Albumin/globulin ratio & -0.1133 & 0.0040 & -0.1107 & 0.0049 \\
\hline Aspartate transaminase & 0.0282 & 0.4660 & 0.0236 & 0.5422 \\
\hline Alanine transaminase & -0.0366 & 0.3441 & -0.0433 & 0.2631 \\
\hline Alkaline phosphatase & 0.0609 & 0.1319 & 0.0699 & 0.0836 \\
\hline Lactate dehydrogenase & 0.0634 & 0.1073 & 0.0495 & 0.2082 \\
\hline Total bilirubin & -0.0459 & 0.2419 & -0.0369 & 0.3460 \\
\hline Cholinesterase & -0.1175 & 0.0094 & -0.1991 & $<0.0001$ \\
\hline$\gamma$-Glutamyl transpeptidase & 0.0558 & 0.1643 & -0.0484 & 0.2274 \\
\hline Total protein & -0.1475 & 0.0002 & -0.1048 & 0.0076 \\
\hline Albumin & -0.1652 & $<0.0001$ & -0.1453 & 0.0002 \\
\hline Blood urea nitrogen & 0.0340 & 0.3802 & 0.0538 & 0.1647 \\
\hline Creatinin & 0.0058 & 0.8808 & 0.0146 & 0.7065 \\
\hline Glomerular filtration rate & -0.0044 & 0.9131 & -0.0556 & 0.1715 \\
\hline Uric acid & 0.0509 & 0.2716 & -0.0233 & 0.6148 \\
\hline Amylase & -0.0890 & 0.0817 & -0.0336 & 0.5113 \\
\hline Total cholesterol & -0.1453 & 0.0005 & -0.1262 & 0.0024 \\
\hline High density lipoprotein cholesterol & -0.0658 & 0.1855 & -0.0503 & 0.3125 \\
\hline Triglyceride & -0.0904 & 0.0579 & -0.1335 & 0.0050 \\
\hline $\mathrm{Na}^{+}$ & 0.0684 & 0.0794 & -0.0467 & 0.2316 \\
\hline $\mathrm{K}^{+}$ & -0.0563 & 0.1495 & -0.0217 & 0.5783 \\
\hline $\mathrm{Cl}^{-}$ & 0.0632 & 0.1052 & 0.0193 & 0.6220 \\
\hline C-reactive protein & 0.1788 & 0.0001 & 0.0491 & 0.2915 \\
\hline White blood cell number & 0.0909 & 0.0188 & 0.0737 & 0.0569 \\
\hline Red blood cell number & -0.0781 & 0.0436 & -0.1152 & 0.0029 \\
\hline Hemoglobin & -0.0565 & 0.1447 & -0.0984 & 0.0110 \\
\hline Hematocrit & -0.0506 & 0.1915 & -0.0971 & 0.0120 \\
\hline Platelet number & -0.0335 & 0.3875 & -0.0762 & 0.0490 \\
\hline Mean platelet volume & -0.0032 & 0.9334 & -0.0021 & 0.9569 \\
\hline Plateletcrit & -0.0323 & 0.4047 & -0.0902 & 0.0197 \\
\hline Platelet distribution width & -0.0174 & 0.6534 & -0.0382 & 0.3245 \\
\hline Blood sugar & 0.0861 & 0.0327 & 0.1512 & 0.0002 \\
\hline Glycated hemoglobin A1c & -0.0320 & 0.4758 & -0.0183 & 0.6830 \\
\hline
\end{tabular}

The data on study individuals were obtained from HD subjects in Chiba Prefectural Sawara Hospital, Higashi Funabashi Hospital, and Port Square Kashiwado Clinic and $\mathrm{TIA}, \mathrm{aCl}$ or cCl patients in Chiba Prefectural Sawara Hospital, Chiba Rosai Hospital, and Chiba Aoba Municipal Hospital. Correlation 
coefficients $(r)$ and $P$ values were calculated via Spearman's correlation analysis. In bold we marked $P<$ 0.05 .

Figures

Figure 1

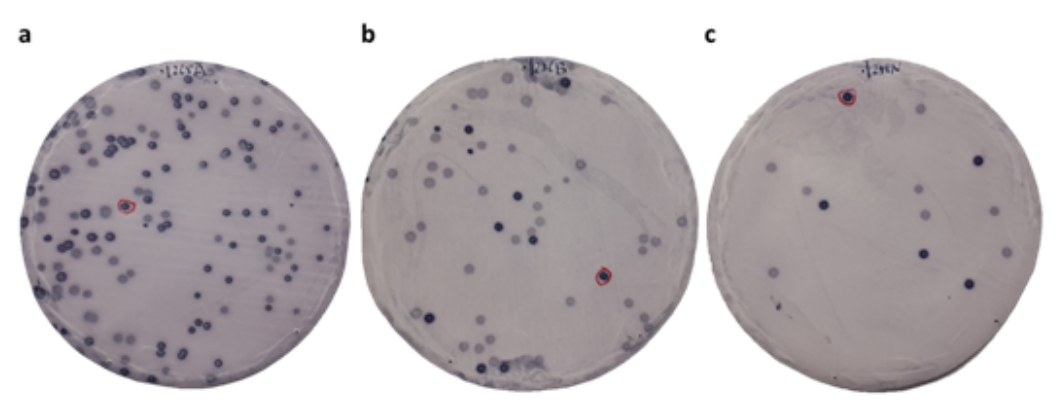

Figure 1 
Immunoscreening of TIA antigens by SEREX. Recombinant expression cloning proteins were blotted on nitrocellulose membranes and reacted with sera originating from 19 TIA patients. Arrows indicate positive phage clones. Positive clones were re-cloned twice to obtain monoclonality.

\section{Figure 2}

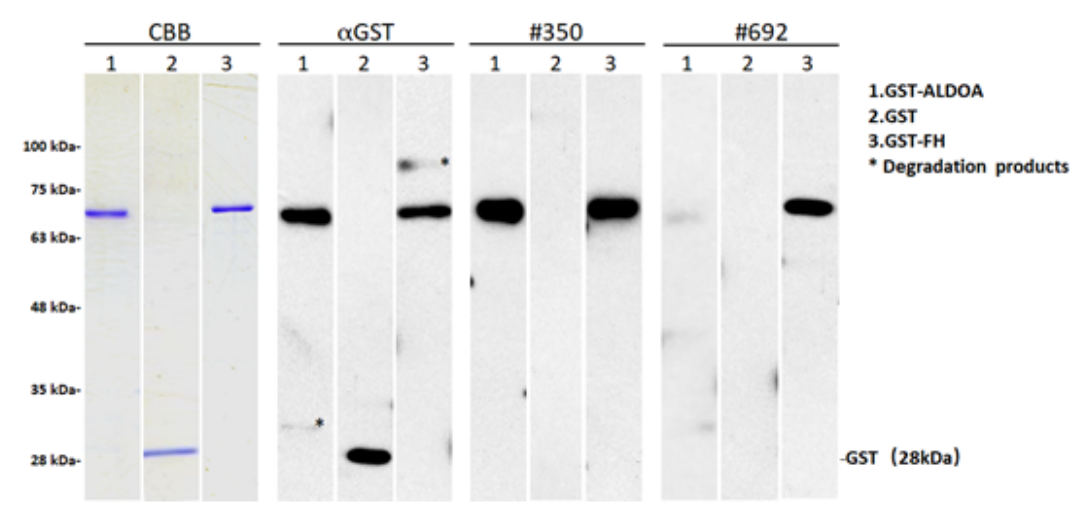

Figure 2

The presence of serum antibodies against ALDOA and FH antigenic proteins. Representative results of Western blotting are shown. The latter showed the detection at the expected sized of all the affinity 
purified glutathione-S-transferase (GST)-fusion antigenic proteins (GST-ALDOA: 65kDa and GST-FH: $67 \mathrm{kDa}$ ). GST and GST fusion proteins were electrophoresed through SDS-polyacrylamide gels. They were subsequently stained with Coomassie Brilliant Blue (CBB) or Western blotting using anti-GST (aGST) or patient sera (\#350 and \#692). The specific reactions to GST-ALDOA and GST-FH are shown. The star represents degradation products post-electrophoresis. On the left of the figure are shown molecular weights.

\section{Figure 3}

a

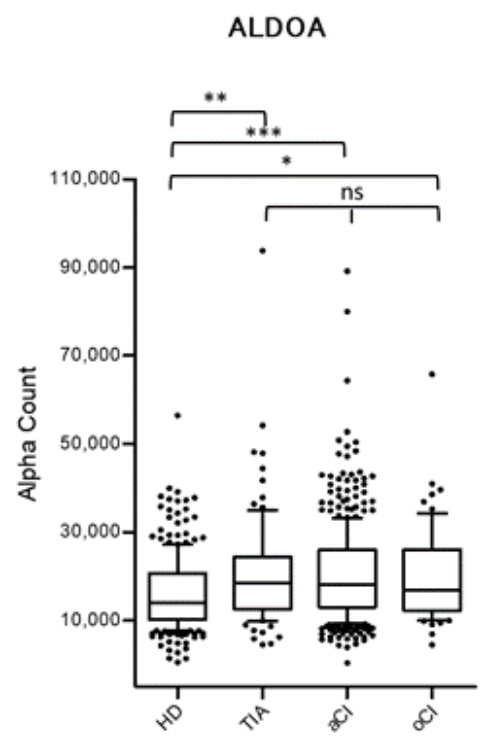

b

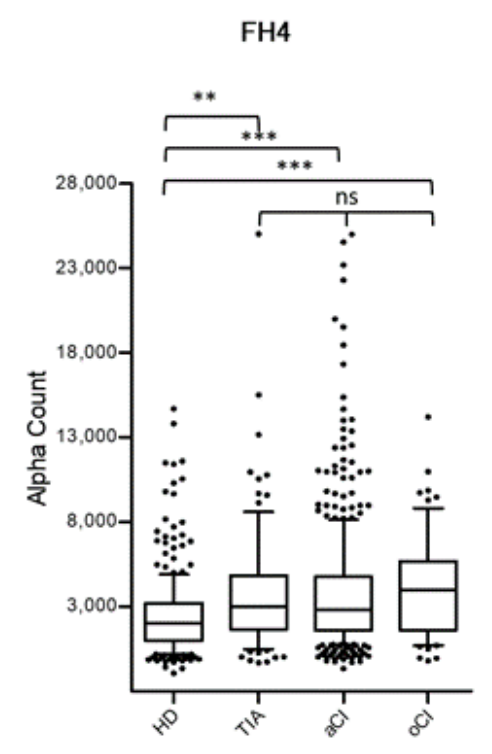

Figure 3 
Comparison of serum ALDOA-Ab and FH-Ab levels between $\mathrm{HDs}$ and $\mathrm{TIA}, \mathrm{aCl}$ or oCl patients. Antigens used were GST-ALDOA (a), and GST-FH (b). Following subtraction of the levels against control GST, serum levels of antibodies were examined by AlphaLISA are shown using a box-whisker. P values vs. HD specimens are shown as the stars. One star indicates $P<0.05$, two stars indicate $P<0.01$, three stars indicate $\mathrm{P}<0.001$. Table 2 shows the averages, $\mathrm{SDs}$, total numbers, and $\mathrm{P}$ values.

\section{Figure 4}
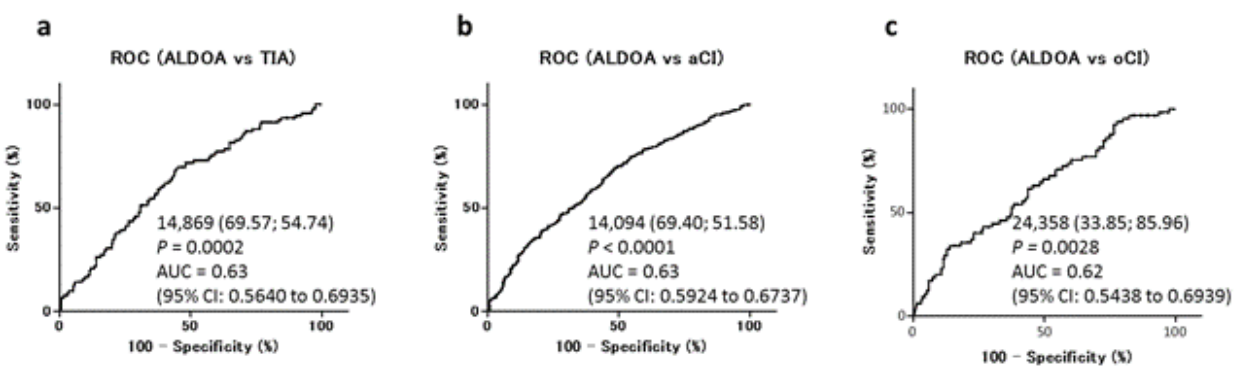

d

e

f
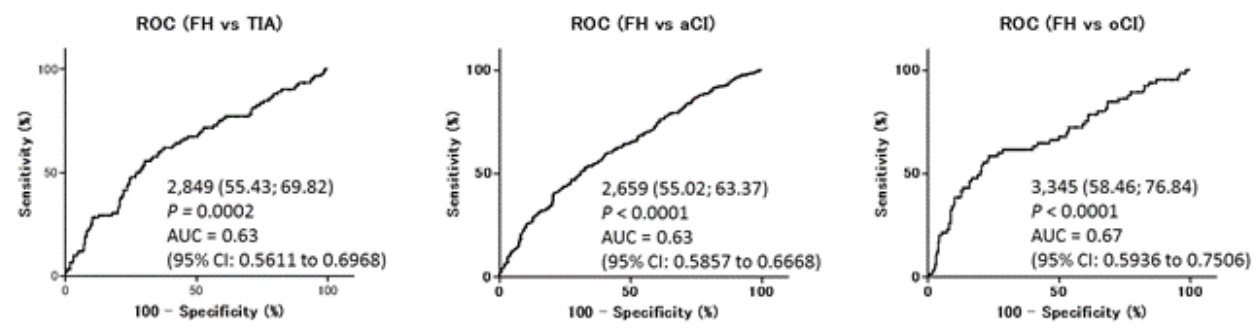

Figure 4 
ROC analysis of ALDOA-Abs and FH-Abs for the prediction of TIA, aCl or oCl. Numbers in the figures indicate cutoff values for marker levels. Numbers in parentheses indicate sensitivity (left) and specificity (right). Areas under the curve (AUC), 95\% confidence intervals (95\% Cl), and P values are shown.

\section{Supplementary Files}

This is a list of supplementary files associated with this preprint. Click to download.

- SupplementaryTable20200110.docx

- WesternblottingCBBaGST.pptx 